Mills, R. F. N. (1955). J. gen. Microbiol. 13, 39-44.

\title{
The Action of Fumagillin on a Bacteriophage of Staphylococcus aureus
}

\author{
By R. F. N. MILLS
}

Virology Section, Research Department, Boots Pure Drug Co. Ltd., Nottingham

SUMMARY: Concentrations of fumagillin which allowed host growth prevented multiplication of phage 209 on Staphylococcus aureus 209. Fumagillin had no action on free phage and little on the adsorption of phage to its host, but when added $15 \mathrm{~min}$. or less after the start of the latent period it prevented phage multiplication. Fumagillin present during adsorption was diluted out during the latent period; the longer fumagillin was present the smaller was the phage yield. Prolonged exposure of the host + phage mixture in Ringer's solution to a concentration of fumagillin too low to prevent phage multiplication lengthened the latent period and decreased the yield of phage, whether fumagillin was present during the burst or not. Under these conditions, when sufficient fumagillin was added to produce a phage-inhibitory concentration and later diluted out, the yield of phage was constant when the dilution was made in the period 0-20 min.

Asheshov, Strelitz \& Hall (1949) reported the isolation of an Aspergillus species which produced two antibiotics active against bacteriophages, one being specific for 'streptophages', the other for some staphylococcal phages. These antibiotics did not act on free phage, or affect adsorption of phage to host. Even when added immediately after infection, the antibiotics did not always prevent a burst. When added 10-15 min. before the start of the second cycle of growth they prevented the second burst. The antibiotic active against staphylococcal phages was later shown (Asheshov, Strelitz \& Hall, 1952) to be identical with the antiphage antibiotic, fumagillin, isolated by Eble \& Hanson (1951) from a strain of Aspergillus fumigatus. As part of a programme of research into virus chemotherapy, the work of Asheshov et al. (1949) on the mode of action of fumagillin has been extended, using the system Staphylococcus aureus strain 209 + phage 209. The results are reported here.

\section{EXPERIMENTAL}

Host. Staphylococcus aureus strain 209 was used as the bacterial host.

Phage. Stock phage 209 of titre $6 \cdot 8 \times 10^{7}$ particles $/ \mathrm{ml}$. was prepared as a bacteriologically sterile suspension in $50 \%$ glycerol. It was stored at $5^{\circ}$ as a 1/100 dilution in Ringer's solution.

Media. Lab-Lemco broth was used throughout as growth medium. Ringer's solution was used when a fluid was required which did not support host growth.

Fumagillin. This was obtained through the courtesy of Dr R. Coghill, Abbotts Laboratories Inc., U.S.A. It was made up as a $0 \cdot 1 \%(\mathrm{w} / \mathrm{v})$ suspension in $10 \%(\mathrm{v} / \mathrm{v})$ acetone in water and stored at $-20^{\circ}$.

Titration of phage. For one-step growth experiments: to $1 \mathrm{ml}$. phage 
suspension in a test tube, $1 \mathrm{ml}$. of a $24 \mathrm{hr}$. culture of Staphylococcus aureus 209 and $3 \mathrm{ml}$. nutrient (tryptic digest) agar were added. After the contents had been mixed, the tubes were sloped and incubated at $37^{\circ}$ overnight before reading. In all other experiments the mixture was poured on $15 \mathrm{ml}$. nutrient agar base.

Methods. These were essentially those of Mills (1953). In all one-step growth experiments, host cells previously suspended for $2 \mathrm{hr}$. in Ringer's solution (Benzer, 1952) were used for adsorption. Times were always measured from the moment of dilution in broth. All work was carried out at $37^{\circ}$. In one-step growth experiments phage liberation occurred over a long period; because of this, measurements of phage yield were made before liberation had ended (usually at $120 \mathrm{~min}$.). Yields were only compared under conditions where the latent period was constant, and as sampling and counting phage was always complete in less than 5 min., it is believed that little error was introduced.

\section{RESULTS}

All points on graphs are the mean of three counts. The latent period of phage 209 on Staphylococcus aureus 209 was about $60 \mathrm{~min}$. (Fig. 3). The yield of phage in one-step growth experiments was usually four to six times phage input. No estimate was made of the percentage adsorption.

Active concentration of fumagillin. In a serial dilution test (Chantrill et al. 1952) fumagillin at $16 \mu \mathrm{g} . / \mathrm{ml}$. allowed host growth but at $0 \cdot 6 \mu \mathrm{g} . / \mathrm{ml}$. prevented phage growth. In one-step growth experiments it prevented phage growth at $0.5 \mu \mathrm{g} . / \mathrm{ml}$. but not at $0.25 \mu \mathrm{g} . / \mathrm{ml}$. Except where otherwise stated, $1 \mu \mathrm{g} . / \mathrm{ml}$. fumagillin was used for this work.

Action of fumagillin on host growth. Fumagillin at $1 \mu \mathrm{g} . / \mathrm{ml}$. had no observable effect on host growth during the first $4 \mathrm{hr}$. as measured by poured plate colony counts. After this time, growth was slightly retarded (Fig. 1).

Action on free phage. When phage 209 was exposed to $2 \mu \mathrm{g}$. fumagillin $/ \mathrm{ml}$. in broth at $37^{\circ}$ for $3 \mathrm{hr}$., the titre remained constant at $1.5 \times 10^{5}$ particles $/ \mathrm{ml}$.

Table 1. The action of fumagillin (1 $\mu \mathrm{g} . / \mathrm{ml}$.) on the adsorption of phage 209 on Staphylococcus aureus 209 in Ringer's solution at $37^{\circ}$

\begin{tabular}{|c|c|}
\hline \multicolumn{2}{|c|}{ Fumagillin } \\
\hline $\begin{array}{c}\text { During } \\
\text { adsorption }\end{array}$ & $\begin{array}{l}\text { During phage } \\
\text { growth }\end{array}$ \\
\hline- & - \\
\hline- & + \\
\hline+ & - \\
\hline+ & + \\
\hline
\end{tabular}

\begin{tabular}{|c|c|}
\hline \multicolumn{2}{|c|}{ Count (plaques/tube) } \\
\hline $10 \mathrm{~min}$. & $120 \mathrm{~min}$. \\
\hline $12,11,12$ & $77,63,64$ \\
\hline $7,7,6$ & $12,12,4$ \\
\hline $17,13,11$ & $42,43,37$ \\
\hline $8,6,13$ & $7,12,9$ \\
\hline
\end{tabular}

Action on adsorption. When fumagillin was present during adsorption and diluted out at the start of the latent period, a burst occurred but the yield of phage was a little smaller (Table 1); hence any action fumagillin had on adsorption could only be small. 


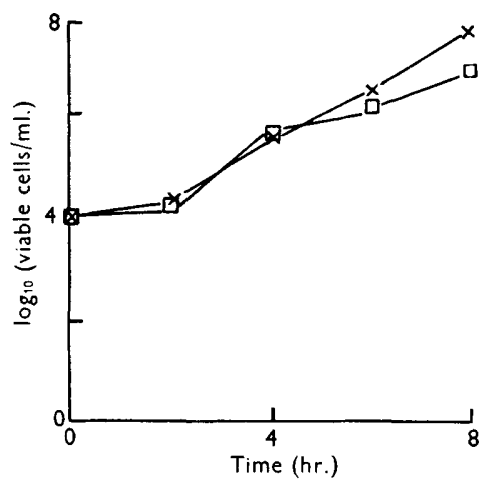

Fig. 1

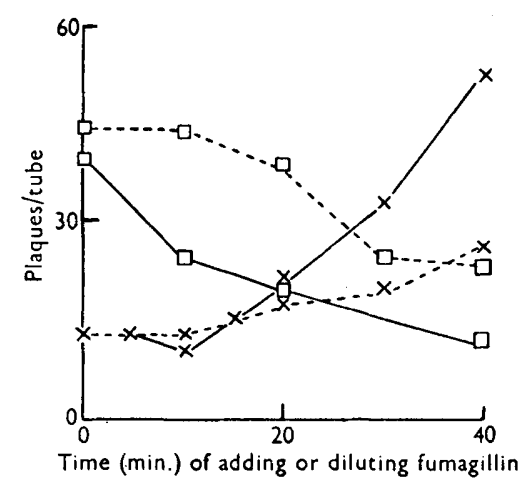

Fig. 2

Fig. 1. The action of fumagillin $(1 \mu \mathrm{g} . / \mathrm{ml}$.) on the growth of Staphylococcus aureus 209 in broth at $37^{\circ} . \times-\times,-$ fumagillin; $\square-\square$, +fumagillin. Growth was estimated by poured-plate colony counts.

Fig. 2. The effect of fumagillin $(1 \mu \mathrm{g} . / \mathrm{ml}$.) on the yield of phage 209 on Staphylococcus aureus 209 in one-step growth experiments. Squares, fumagillin initially present at $1 \mu \mathrm{g} . / \mathrm{ml}$., diluted to $0.1 \mu \mathrm{g} . / \mathrm{ml}$. at different times; crosses, fumagillin added to $1 \mu \mathrm{g} . / \mathrm{ml}$. at different times. Dotted lines, preliminary exposure of host and phage to $0 \cdot 1 \mu \mathrm{g} . / \mathrm{ml}$. fumagillin for $90 \mathrm{~min}$. before transfer to broth. Full lines, no preliminary exposure to fumagillin. Counts were made by sloping $1 \mathrm{ml}$. samples and counting plaques after incubation overnight at $37^{\circ}$.

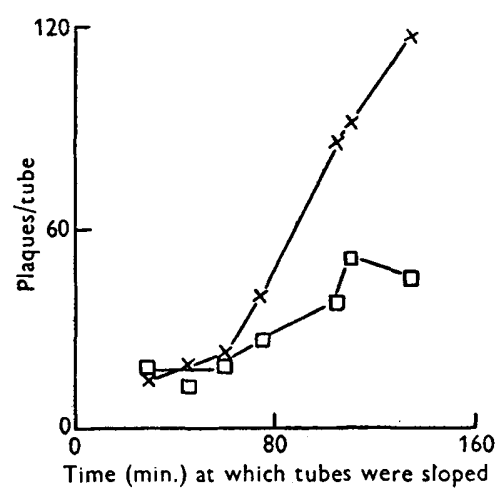

Fig. 3

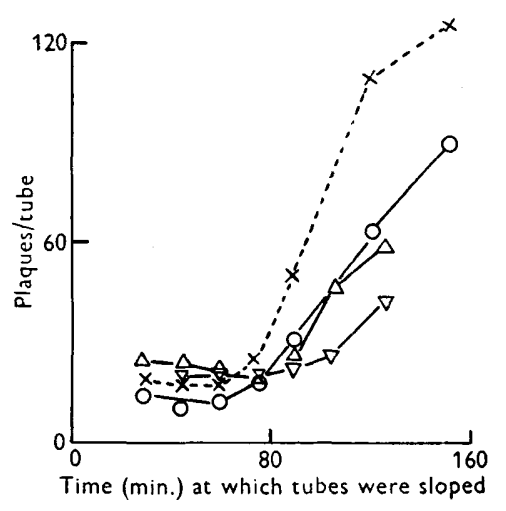

Fig. 4

Fig. 3. The effect of adding fumagillin $(1 \mu \mathrm{g} . / \mathrm{ml}$. $)$ at $30 \mathrm{~min}$. on the latent period of phage 209 on Staphylococcus aureus 209 in broth. $\times-\times,-$ fumagillin; $\square-\square$, + fumagillin. Counts were made by sloping $1 \mathrm{ml}$. samples and counting plaques after incubation overnight at $37^{\circ}$.

Fig. 4. The effect of diluting fumagillin from $1 \mu \mathrm{g} . / \mathrm{ml}$. to lower concentrations on the latent period of phage 209 on Staphylococcus aureus 209 in broth. $\times$ - - $\times$, control - fumagillin; $\mathrm{O}-\mathrm{O}$, fumagillin diluted to $0.002 \mu \mathrm{g} . / \mathrm{ml}$. at $0 \mathrm{~min}$.; $\Delta-\Delta$, fumagillin diluted to $0.1 \mu \mathrm{g} . / \mathrm{mI}$. at $0 \mathrm{~min}$.; $\nabla-\nabla$, fumagillin diluted to $0 \cdot 1 \mu \mathrm{g} . / \mathrm{ml}$. at $40 \mathrm{~min}$. Except in the control, fumagillin was present during adsorption at a concentration of $1 \mu \mathrm{g} . / \mathrm{ml}$. Counts were made by sloping $1 \mathrm{ml}$. samples and counting plaques after incubation overnight at $37^{\circ}$. 


\section{Action on intracellular phage}

Time of action. Adsorption was carried out in the absence of fumagillin which was added at various times after dilution into broth. There was no burst when fumagillin was added at 15 min., but a small burst when it was added at 20 min. (Fig. 2). This behaviour differed from that reported by Asheshov et al. (1949), who found that fumagillin did not prevent a burst even if added when phage and host were mixed. When fumagillin was added at $30 \mathrm{~min}$., the latent period was not affected (Fig. 3).

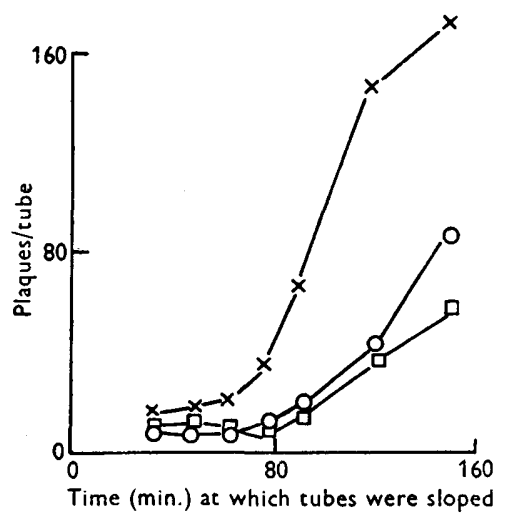

Fig. 5

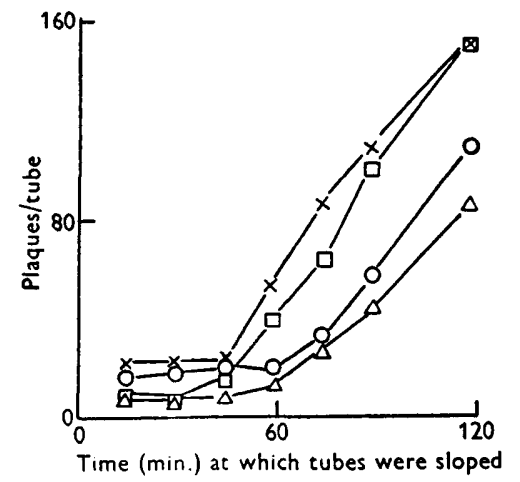

Fig. 6

Fig. 5. Effect of preliminary exposure to fumagillin $(0 \cdot 1 \mu \mathrm{g} . / \mathrm{ml}$.) on the latent period of 209 phage on Staphylococcus aureus 209 in broth. $\times-\times$, control - fumagillin throughout; $\bigcirc-O$, fumagillin absent during phage growth; $\square-\square$, fumagillin $(0 \cdot 1 \mu \mathrm{g} . / \mathrm{ml}$.) present during phage growth. After adsorption of phage to host, the mixture was held at $37^{\circ}$ in Ringer's solution for $1 \frac{1}{2} \mathrm{hr}$. in the presence or absence of fumagillin.

Fig. 6. The action of fumagillin $(0 \cdot 1 \mu \mathrm{g} . / \mathrm{ml}$.) on the liberation of intracellular 209 phage from Staphylococcus aureus 209 by cyanide. $\times-\times$, control, - fumagillin-cyanide; $\mathrm{O}-\mathrm{O}$, +fumagillin - cyanide; $\square-\square$, - fumagillin + cyanide; $\Delta-\triangle$, + fumagillin + cyanide. KCN was added to a final concentration of $0.03 \mathrm{M}$ at the times shown. At $150 \mathrm{~min}$. it was diluted 1:100 and $1 \mathrm{ml}$. samples were then counted. When KCN was omitted, samples were diluted $1: 100$ at the times shown, and $1 \mathrm{ml}$. samples counted immediately.

Effect of diluting out. Fumagillin was present during adsorption and after transfer to broth. At various times during the latent period a dilution was made to a fumagillin concentration of $0 \cdot 1 \mu \mathrm{g} . / \mathrm{ml}$., and this concentration was not altered for the rest of the experiment. The later the suspension containing fumagillin was diluted the greater was the effect on phage yield (Fig. 2): the latent period was increased by about $25 \mathrm{~min}$. irrespective of the time of dilution (Fig. 4); this increase was found to be due to the residual fumagillin. When the fumagillin was diluted to $0.002 \mu \mathrm{g} . / \mathrm{ml}$. immediately after adsorption, the latent period was not affected (Fig. 4).

Effect of exposure to fumagillin at $0 \cdot 1 \mu \mathrm{g} . / \mathrm{ml}$. After adsorption in the absence of fumagillin, the host + phage mixture was diluted in Ringer's solution containing fumagillin $0.1 \mu \mathrm{g} . / \mathrm{ml}$. The mixture was held at $37^{\circ}$ for $90 \mathrm{~min}$. and 
then diluted in broth. Under these conditions, the latent period was increased and the phage yield decreased (Fig. 5). The presence of $0 \cdot 1 \mu \mathrm{g}$. fumagillin $/ \mathrm{ml}$. during the actual burst had no further effect on the latent period, but resulted in a still smaller yield of phage (Fig. 5).

Preliminary exposure to $\mathbf{0} \cdot \mathbf{1} \mu \mathrm{g}$. fumagillin $/ \mathrm{ml}$. in the above manner, did not affect the time of action of fumagillin $(1 \mu \mathrm{g} . / \mathrm{ml}$.) added at different times during the latent period (Fig. 2). When, however, fumagillin was added to $1 \mu \mathrm{g} . / \mathrm{ml}$. at the start of phage growth, and subsequently diluted to $0 \cdot 1 \mu \mathrm{g} . / \mathrm{ml}$., for the period 0-20 min., the yield of phage was independent of time of dilution but decreased when the dilution was made at 30 min. (Fig. 2).

Effect of fumagillin on the appearance of intracellular phage. Fumagillin was present at a concentration of $1 \mu \mathrm{g} . / \mathrm{ml}$. during adsorption and was diluted to $0.1 \mu \mathrm{g} . / \mathrm{ml}$. on transfer to broth. At various times samples were taken and cyanide added to a final concentration of $0.03 \mathrm{M}$ to liberate any intracellular phage particles (Doermann, 1951). Each mixture was left for 150 min., diluted 1/100 and $1 \mathrm{ml}$. samples sloped. An increase in phage titre was found only when cyanide was added $15 \mathrm{~min}$. before the end of the latent period (i.e. at $60 \mathrm{~min}$.) or at times later than this. In the absence of fumagillin, intracellular phage was also detected $15 \mathrm{~min}$. before the end of the normal latent period (i.e. at 45 min., Fig. 6). Under the conditions used, cyanide had no action on free phage 209.

\section{DISCUSSION}

Asheshov et al. (1949) found that their antibiotic had no action on free phage, on host growth or on the phage adsorption on its host. They also found that their antibiotic did not always prevent a burst even when added at the time of mixing phage and host. In the present work fumagillin prevented phage multiplication when added during the first $15 \mathrm{~min}$. of phage growth. This discrepancy might be due to differences in a number of factors: experimental conditions, phage and host used, purity of the antibiotic, or even the antibiotic itself as it is not clear which of their two Asheshov et al. (1949) were using.

From the results reported above, fumagillin appears to have at least two different actions on the Staphylococcus aureus 209 + phage 209 system. At low concentrations fumagillin lengthens the latent period and decreases the yield of phage; at high concentrations fumagillin (when added early enough) has a true virustatic action, and (when added late enough to allow some phage growth) no action on the latent period. It seems reasonable to assume that when fumagillin is initially present at $1 \mu \mathrm{g} . / \mathrm{ml}$. and later diluted out, the decreased yield of phage with increased time of dilution reflects both the 'latent period effect', which is only slowly established, and the virustatic effect. The experiments in which fumagillin was always present at a concentration of at least $0 \cdot 1 \mu \mathrm{g} . / \mathrm{ml}$. were attempts to study the virustatic effect by itself. The results are consistent with the hypothesis that fumagillin interferes with a stage in the development of vegetative phage. This stage occurs about 20 min. after the start of phage growth. As the first detectable intracellular 
phage is not found till about $\mathbf{1 5} \mathrm{min}$. before the end of the latent period (i.e. at $45 \mathrm{~min}$. in the absence of fumagillin and at $60 \mathrm{~min}$. in $0 \cdot 1 \mu \mathrm{g}$. fumagillin $/ \mathrm{ml}$.) the action of fumagillin, unlike that of proflavine on T2 phage of Escherichia coli B (Foster, 1948), is not on phage maturation. Neither does it act on the stages immediately after infection, as does a phenanthridine on some phages of Pseudomonas aeruginosa (Mills, 1953; Dickinson, 1954). The work reported here does not allow any hypothesis about the nature of the stage in phage synthesis inhibited, but the specificity of action of fumagillin (Asheshov et al. 1949) suggests that the stage may be one peculiar to a few staphylococcal phages.

I wish to thank Dr Löis Dickinson for her advice and criticism in this work, Mr C. E. Coulthard for his interest in it, and Miss M. L. Rose for technical assistance.

\section{REFERENCES}

Asheshov, I. N., Strelitz, F. \& Hall, E. A. (1949). Antibiotics active against bacterial viruses. Brit. J. exp. Path. 30, 175.

Asheshov, I. N., Strelitz, F. \& Hall, E. A. (1952). Identity of fumagillin and phagopedin sigma. Antibiot. \& Chemother. 2, 361.

Benzer, S. (1952). Resistance to ultraviolet light as an index to the reproduction of bacteriophage. J. Bact. 63, 59.

Chantrill, B. H., Coulthard, C. E., Dickinson, L., Inkley, G. W., Morris, W. \& Pyle, A. H. J. (1952). The action of plant extracts on a bacteriophage of Pseudomonas pyocyanea and on influenza A virus. J. gen. Microbiol. 6, 74.

Dickinson, L. (1954). The behaviour of a temperate phage of Pseudomonas aeruginosa compared with that of a serologically related virulent mutant. J. gen. Microbiol. 11, 105.

Doermann, A. H. (1951). Intracellular phage growth as studied by premature lysis. Fed. Proc. 10, 591.

Eble, T. E. \& Hanson, F. R. (1951). Fumagillin, an antibiotic from Aspergillus fumigatus H-3. Antibiot. \& Chemother. $1,54$.

Foster, R. A. C. (1948). An analysis of the action of proflavine on bacteriophage growth. J. Bact. 56, 795.

Mills, R. F. N. (1953). The action of 2:7-bis(2'-dihydroglyoxalinyl)-9-phenylphenanthridine on a bacteriophage of Pseudomonas pyocyanea. Brit. J. Pharmacol. 8, 143. 